\title{
NMDA Receptor Antagonists Decrease GABA Outflow from the Septum and Increase Acetylcholine Outflow from the Hippocampus: A Microdialysis Study
}

\author{
M. G. Giovannini, D. Mutolo, ${ }^{a}$ L. Bianchi, A. Michelassi, and G. Pepeu \\ Department of Preclinical and Clinical Pharmacology, University of Florence, 50134 Florence, Italy
}

The modulation of the septohippocampal cholinergic path. way by glutamatergic or GABAergic inputs was studied by monitoring the outflow of ACh collected via a transversal microdialysis probe implanted into the hippocampus and other brain areas of freely moving rats. In one set of experiments a transversal microdialysis membrane was inserted in the dorsal hippocampus, drugs were administered intracerebroventricularly through a cannula implanted in the lateral ventricle, and $\mathrm{ACh}$ outflow in the dialysate was measured by an HPLC method with an electrochemical detector. The dialysis membrane was usually perfused with Ringer's solution containing $7 \mu \mathrm{M}$ physostigmine sulfate. Intracerebroventricular injections of the NMDA antagonists 3-((RS)2-carboxypiperazin-4-yl)-propyl-1-phosphonic acid (CPP; 1$50 \mathrm{nmol})$, MK801 (0.5-20 nmol), and $\mathrm{D}(-)$-2-amino-7-phosphonoheptanoic acid (100 $\mathrm{nmol}$ ) brought about an increase in hippocampal ACh outflow while the non-NMDA antagonist 6,7-dinitroquinoxaline-2,3-dione $(0.25-20 \mathrm{nmol})$ was without effect. The increase in ACh outflow following CPP administration was dose dependent and reached a maximum of about $500 \%$. It was abolished by TTX $(0.5 \mu \mathrm{M})$ delivered locally to the hippocampus via the dialysis membrane and prevented by intracerebroventricular injection of the GABA agonist muscimol ( $5 \mathrm{nmol})$. In a second set of experiments, one microdialysis membrane was inserted in the dorsal hippocampus to detect $\mathrm{ACh}$ outflow and another in the septum to administer drugs locally and at the same time detect septal GABA outflow. The septal dialysis membrane was perfused with Ringer's solution without physostigmine, and GABA levels in the dialysate were measured by an HPLC method with a fluorescence detector. CPP $(100 \mu \mathrm{M})$ perfused through the septum resulted in a decrease in septal GABA outflow and a concomitant increase in hippocampal $A C h$ outflow. Muscimol (100 $\mu \mathrm{m})$ administration into the septum abolished the effect of CPP on hippocampal ACh outflow but did not affect septal GABA outflow. These results demonstrate that in the septum NMDA receptors tonically activate

\footnotetext{
Received Jan. 22, 1993; revised June 14, 1993; accepted Aug. 20, 1993.

This work was supported by a grant from MURS1. We are grateful to Prof. A. Nistri (ISAS., Trieste, Italy) for helpful discussions and to Dr. L. Giovannelli for preparing the histological sections.

Correspondence should be sent to Prof. Giancarlo Pepeu, M.D., Department of Preclinical and Clinical Pharmacology, University of Florence, Viale Morgagni 65, 50134 Florence, Italy.

Present address: Department of Physiological Sciences, University of Florence, Viale Morgagni 63, 50134 Florence, Italy.

Copyright (C) 1994 Society for Neuroscience $0270-6474 / 94 / 141358-08 \$ 05.00 / 0$
}

GABAergic neurons which in turn inhibit the cholinergic septohippocampal neurons.

[Key words: hippocampus, septum, NMDA receptors, ACh outflow, GABA outflow, microdialysis]

The septohippocampal pathway, which originates from the medial septum and the nucleus of the diagonal band and projects diffusely to the Ammon's horn and dentate gyrus of the hippocampus, provides the main cholinergic input to the hippocampus (Nicoll, 1985). The majority of the septohippocampal fibers are rich in AChE and ChAT (Lewis and Shute, 1967; Lewis et al., 1967; Cuello and Sofroniew, 1984). Electrical stimulation of the medial septum is followed by an increase in ACh outflow from the hippocampus (Szerb, 1967) and enhances via muscarinic receptors hippocampal spikes evoked by commissural stimulation (Krnjevic and Ropert, 1982).

The physiological and pharmacological properties of the medial septal neurons have been extensively studied (McLennan and Miller, 1974a,b; Lamour et al., 1984; Segal, 1986). Electrophysiological data demonstrate that the medial septal cholinergic neurons are regulated by intrinsic interneurons through a GABAergic mechanism (McLennan and Miller, 1974a,b; Lamour et al., 1984; Segal, 1986; Dutar et al., 1989).

Biochemical and pharmacological evidence indicates that there is also a glutamatergic hippocamposeptal pathway arising from the pyramidal neurons of the Ammon's horn and projecting to the lateral scptum (Zaczck ct al., 1979; Jöcls and Urban, 1984; Stevens and Cotman, 1986), where it impinges on GABAergic interneurons (Malthe-Sörennsen et al., 1980). These in turn project to the medial septum and are responsible for the major inhibitory input to the medial septal cholinergic neurons (McLennan and Miller, 1974a,b; Dutar et al., 1985). On the other hand, pyramidal and nonpyramidal neurons from the hippocampus send more sparse but still important projections directly to the neurons of the medial septum (Gaykema et al., 1991). Therefore, the medial septal area can be considered a relay station of efferents to and afferents from the hippocampus. Vinogradova et al. (1980) and Dutar et al. (1987) suggested the existence of a tonic inhibitory input from the hippocampus to septal neurons.

The aim of our work was to investigate the modulation of the septohippocampal cholinergic neurons by glutamatergic inputs. For this purpose we studied the outflow of endogenous $\mathrm{ACh}$ from the hippocampus as an index of functional activity of cholinergic neurons (Pepeu, 1973). ACh outflow from hippocampus was studied by means of the transversal microdialysis technique (Imperato and Di Chiara, 1984) in freely moving rats. 


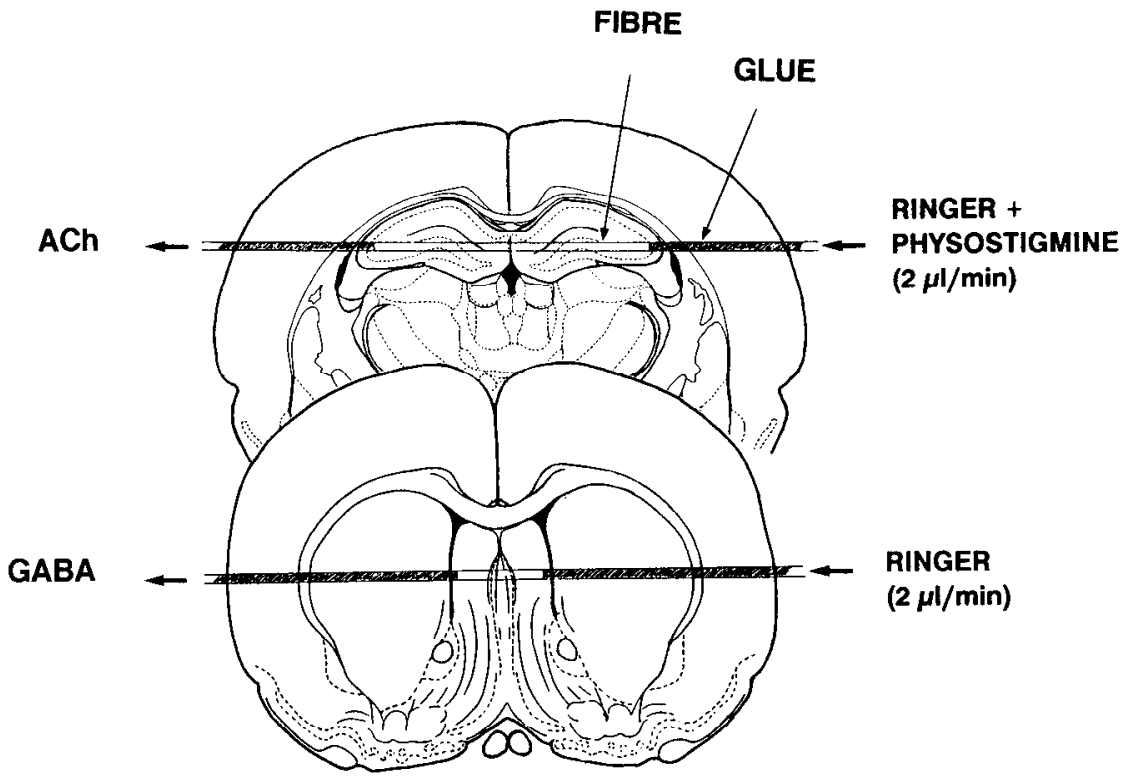

Figure 1. Schematic diagram showing the positioning of the dialysis membrane in the septum and hippocampus. For stereotaxic coordinates, see Materials and Methods.

We also implanted a second microdialysis probe in the septum. By means of this "dual membrane technique" we perfused the drugs directly into the septum and at the same time we studied the effects of drugs on ACh outflow from the terminals of the septohippocampal neurons. Therefore, by this procedure it has been possible to study the effect of local application of drugs on two sequential steps in the same neuronal circuitry.

A preliminary report of this study has been presented (Giovannini et al., 1992).

\section{Materials and Methods}

Animal housing and surgery. Male adult Charles River Wistar rats weighting 250-300 gm were used. They were housed in groups of three with free access to food and water and kept on a $12 \mathrm{hr}$ light $/ 12 \mathrm{hr}$ dark cycle. The rats were anaesthetized with chloral hydrate $(400 \mathrm{mg} / \mathrm{kg}$, i.p.) and placed in a stereotaxic frame (Stellar, from Stoelting Co., Wood Dale, IL). Microdialysis tubes were inserted transversely into the septum, dorsal hippocampi, and both striata following the procedure described by Wu et al. (1988). The microdialysis tubing (AN 69 membrane, Dasco, Italy) was covered with Super-Epoxy glue along the whole of its length except for a region corresponding to the brain areas to be studied ( $2 \mathrm{~mm}$ for the septum, $6 \mathrm{~mm}$ for the dorsal hippocampus, and two sections of $3.5 \mathrm{~mm}$ separated by a glued central zone $2.5 \mathrm{~mm}$ long for the striata). The coordinates used for the implantation of the microdialysis tubing were as follows (Paxinos and Watson, 1982): for the septum, AP $+0.9 \mathrm{~mm}$ and $\mathrm{H} 5 \mathrm{~mm}$ from bregma; for the dorsal hippocampi, AP $-3.3 \mathrm{~mm}$ and $\mathrm{H} 3.3 \mathrm{~mm}$ from bregma; for the striata, AP $0.0 \mathrm{~mm}$ and $\mathrm{H} 5 \mathrm{~mm}$ from bregma. When necessary, a polyethylene cannula (length, $4 \mathrm{~mm}$ ) was inserted in the lateral ventricle to allow the intracerebroventricular injection of the drugs. The coordinates used were AP $-1.5 \mathrm{~mm}, \mathrm{~L}-1.5 \mathrm{~mm}$ from bregma. All coordinates were referred to bregma, with bregma and lambda on a horizontal plane.

Microdialysis procedure. One day after surgery each rat was placed in a Plexiglas cage. In one set of experiments a microdialysis probe was placed in the hippocampus or in the striatum and a polyethylene cannula in the lateral ventricle, when nccessary. The microdialysis probe was perfused with Ringer's solution $\left(\mathrm{NaCl}, 147 \mathrm{~mm} ; \mathrm{CaCl}_{2}, 1.2 \mathrm{~mm} ; \mathrm{KCl}\right.$ $4.0 \mathrm{~mm}$; containing $7 \mu \mathrm{M}$ physostigmine sulfate) at a constant flow rate of $2 \mu \mathrm{l} / \mathrm{min}$ using a microperfusion pump (Carnegie Medicine, model CMA $/ 100$, Stockholm, Sweden). The content of ACh and choline (Ch) in the dialysate was analyzed by HPLC as described below. Drugs were administered either locally dissolved in Ringer's solution or by intracerebroventricular injection dissolved in $5 \mu \mathrm{l}$ of saline (flow rate, $5 \mu \mathrm{l} /$ $15 \mathrm{sec})$.

In the "dual membrane" set of experiments the rats were implanted with the dialysis membrane both in the septum and hippocampus (see the schematic diagram in Fig. 1). The microdialysis probe implanted in the septum was perfused with Ringer solution without physostigmine. Drugs were administered in the septum dissolved in Ringer's solution. The dialysates from the septum and hippocampus were collected for the analysis of GABA and ACh, respectively, as described below.

After $1 \mathrm{hr}$ settling period the dialysate was collected at $20 \mathrm{~min}$ intervals and directly assayed for ACh and Ch or GABA. After collecting the first three or four samples to measure the basal outflow, drugs were injected intracerebroventricularly or delivered locally to the septum or hippocampus through the microdialysis membrane.

Histological control. At the end of the experiment the rats were anesthetized with urethane $(1.2 \mathrm{gm} / \mathrm{kg}$, i.p.) and killed by decapitation. In order to verify the exact positioning of the intracerebroventricular cannula, $5 \mu$ l of China ink was injected via the cannula before decapitation. The brain was rapidly removed and placed in a vial containing $10 \mathrm{ml}$ of $9 \%$ phosphate-buffered formaldehyde solution. Two or three days later the brain was frozen with liquid $\mathrm{CO}_{2}$ and coronal slices were cut using a freezing microtome. The $50-\mu \mathrm{m}$-thick slices were observed under light microscopy (Leitz, Dialva $20 \mathrm{~EB}$ ) to verify the positioning of the dialysis membrane. Data obtained from rats in which the dialysis membrane was positioned outside the structure under investigation and/or the intracerebroventricular cannulas outside the lateral ventricle were discarded. The conditions of the septal neurons around the probe were checked at the end of the experiment by staining coronal sections of paraformaldchydc-fixed brains with Richardson's solution (modified Nissl staining).

"In vitro" recovery experiment. In order to evaluate the recovery of $\mathrm{ACh}, \mathrm{Ch}$, and GABA through the microdialysis tubing "in vitro," recovery experiments were performed as described in Giovannini et al. (1991a). The recovery of $\mathrm{ACh}$ and $\mathrm{Ch}$ from the dialysis membrane was $56 \pm 0.6 \%$ and $60 \pm 0.7 \%$, and $58 \pm 2.9 \%$ and $64 \pm 3.2 \%$ for the membrane used for the hippocampus and striatum, respectively. The recovery of GABA was $38 \pm 8.0 \%$. ACh, $\mathrm{Ch}$, and $\mathrm{GABA}$ values reported here were not corrected for recovery. All the recovery experiments were performed at room temperature.

Assay of $A C h$ and $C h$ in the dialysate. ACh and $\mathrm{Ch}$ were directly assayed in the dialysate using an HPLC method with an electrochemical detector as described by Damsma et al. (1987a) and Giovannini et al. (199la,b). Briefly, ACh and Ch were separated on a cation exchange column prepared by loading a reverse phase column (Chromspher 5 C18, Chrompack) with sodium lauryl sulfate $(0.5 \mathrm{mg} / \mathrm{ml})$ as described by Damsma et al. (1987b). The mobile phase consisted of $0.2 \mathrm{~m}$ phosphate buffer (pH 8.0) containing $5 \mathrm{mM} \mathrm{KCl,} 1 \mathrm{~mm}$ tetramethylammonium (TMA), and $0.3 \mathrm{~mm}$ EDTA. The flow rate was $0.7 \mathrm{ml} / \mathrm{min}$. ACh was hydrolyzed by $\mathrm{AChE}$ to acetate and $\mathrm{Ch}$ in a postcolumn enzyme reactor: $\mathrm{Ch}$ was oxidized by $\mathrm{Ch}$ oxidase to produce betaine and hydrogen peroxide. Hydrogen peroxide was electrochemically detected by a platinum electrode at $+250 \mathrm{mV}$. For the quantitative analysis of $\mathrm{ACh}$ and $\mathrm{Ch}$ we constructed a calibration curve by spiking the Ringer's solution 

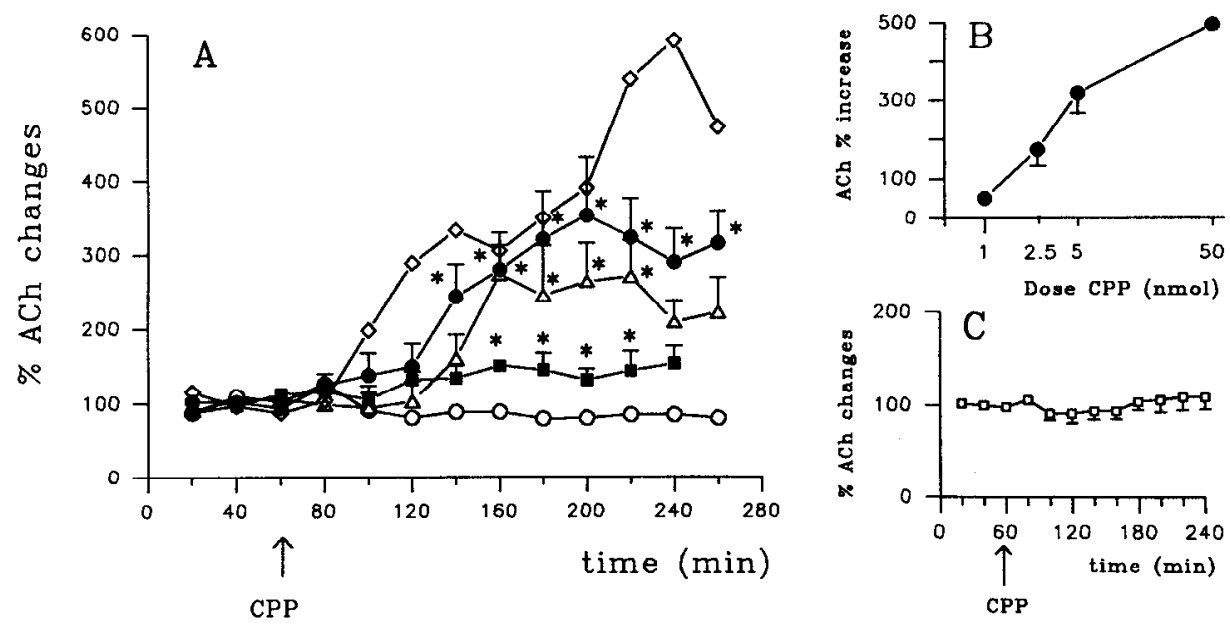

Figure 2. A, Effect of CPP administration (dissolved in $5 \mu$ l saline, i.c.v.) on the outflow of ACh from the hippocampus of freely moving rats. ACh outflow is expressed as percentage changes over the mean of the first three basal samples, as controls (mean \pm SEM of at least four independent experiments, except for $50 \mathrm{nmol}$, for which two rats were used; see Results). Data points represent controls ( $5 \mu 1$ saline, i.c.v.; open circles), and CPP (dissolved in $5 \mu \mathrm{l}$ saline, i.c.v.) at $1 \mathrm{nmol}$ (solid squares), $2.5 \mathrm{nmol}$ (open triangles), $5 \mathrm{nmol}$ (solid circles), and $50 \mathrm{nmol}$ (open diamonds). Dialysate was collected for $60 \mathrm{~min}(3 \times 20 \mathrm{~min}$ fractions) before injection of CPP or saline, shown by the arrow. Differences were evaluated versus the basal samples by means of ANOVA for repeated measures followed by Newman-Keuls post hoc comparison test (*, $p$ at least $<0.05$ vs basal outflow). $B$, Dose-response curve of the effect of CPP on the outflow of ACh from the hippocampus. Data reported on abscissa are the maximum percentage increase over basal outflow at each dose tested (each point represents the mean \pm SEM of at least four experiments on different rats, with the exception of the dose $50 \mathrm{nmol}$, which was administered to only two rats, as explained in Results). $C$, Effect of CPP administration ( 5 $\mathrm{nmol}$, dissolved in $5 \mu \mathrm{l}$ saline, i.c.v.) on the outflow of $\mathrm{ACh}$ from the striatum of freely moving rats. ACh outflow is expressed as percentage changes over the mean of the first three basal samples, as controls (mean \pm SEM of six independent experiments). Dialysate was collected for 60 min (3 $\times 20$ min fractions) before injection of CPP, shown by the arrow.

with standard $\mathrm{ACh}$ and $\mathrm{Ch}$ in the concentration range we expected to find in the dialysates. Three or four concentrations for each calibration curve were then injected at the beginning and the end of the analysis, and the heights of the recorded peaks were then plotted against the concentrations. A regression line was calculated and quantitation of unknown samples was carried out by the method of inverse prediction. Under these experimental conditions the sensitivity limit ( $s: n$ ratio, 3:1) was 500 fmol for $\mathrm{ACh}$ and 250 fmol for $\mathrm{Ch}$.

Assay of GABA in the dialysate. GABA analysis was carried out by an HPLC method after derivatization of the amino acid. The equipment (Perkin-Elmer) consisted of a gradient pump series 3B and 650-10S fluorometric detector fitted with a $5 \mu$ l flow cell. The excitation wavelength was $340 \mathrm{~nm}$ and the emission wavelength was $455 \mathrm{~nm}$. A Shimadzu C-R4A Chromatopac integrator was connected to the detector. A nucleosil C18 column ( $200 \mathrm{~nm} \times 4 \mathrm{~mm}$ i.d.; particle size $5 \mu \mathrm{m}$ ) was used. The mobile phase consisted of methanol-potassium acetate $(0.1$ M) plugged to $\mathrm{pH} 5.5$ by glacial acetic acid and was run at $1.5 \mathrm{ml} / \mathrm{min}$ in two linear steps from $25 \%$ to $90 \%$ methanol $(13 \mathrm{~min})$ followed by an isocratic hold for a further $3 \mathrm{~min}$.

GABA was derivatized with $O$-phthalaldehyde (OPA) as described by Lenda and Svenneby (1980), except that the OPA concentration was $0.3 \mathrm{mg} / \mathrm{ml}$ and $50 \mathrm{~mm} \mathrm{HCl}$ was used to dissolve the sample in preparation for the chromatographic run. The increased OPA concentration was necessary to ensure complete derivatization of the other amino acids. Homoserine was added as internal standard. One volume $(10 \mu \mathrm{l})$ of dialysate was mixed with two volumes of the derivatization reagent solution in glass capillaries. The contents were mixed and injected after $60 \mathrm{sec}$. Standard curves showed a linear relationship between the amount of fluorescence and the quantity of GABA applied to the column over the range $0.1-100 \mathrm{pmol}$. Inder these experimental conditions the sensitivity limit (signal-to-noise ratio $>3$ ) was $32 \mathrm{fmol}$.

Chemicals. All reagents were of analytical grade. Physostigmine sulfate, OPA, homoserine, tetrodotoxin (TTX), AChE (E.C. 3.1.1.7., grade VI-S), and Ch oxidase (E.C. 1.1.3.17) were purchased from Sigma Chemical Co. (St. Louis, MO); 3-((RS)-2-carboxypiperazin-4-yl)-propyl-1phosphonic acid (CPP), D(-)-2-amino-7-phosphonoheptanoic acid (DAP7), and 6,7-dinitroquinoxaline-2,3-dione (DNQX), from Tocris Neuramin (Bristol, England); MK801, from Research Biochemicals Inc. (Natick, MA); and muscimol, from Serva (Heidelberg, Germany).

Statistical analysis. ACh and GABA outflow rates were expressed as percentage variation over basal output which (for each group of exper- iments) was the mean ( \pm SEM) of all predrug determinations. Significant differences were statistically evaluated on the percentage values using the ANOVA for repeated measures followed by Newman-Keuls multiple comparison test. Differences were considered significant at $p<$ 0.05 .

\section{Results}

Basal ACh outflow from the hippocampus of freely moving rats was $2.93 \pm 0.17 \mathrm{pmol} / 20 \mathrm{~min}($ mean $+\mathrm{SFM} ; n$ rats $=42)$ and remained stable throughout the experiment ( $4 \mathrm{hr}$ or more). Saline intracerebroventricular injections were followed by a small (maximum of 30-40\%) increase in the outflow of $\mathrm{ACh}$ from the hippocampus, lasting only one collection period, associated with the handling of the animal and probably due to stress. When the membrane was positioned outside the hippocampus, ACh levels in the dialysate were very low, near the sensitivity limit of the detection method, and no drug effect was observed. These latter data were thus discarded.

The initial efflux of $\mathrm{Ch}$ from the hippocampus was $51.9 \pm$ $2.6 \mathrm{pmol} / 20 \mathrm{~min}$ (mean $\pm \mathrm{SEM} ; n$ rats $=44$ ) and decreased rapidly during the first $60 \mathrm{~min}$ of collection to a new steady state level, at about $50 \%$ of the initial value, $120 \mathrm{~min}$ after the beginning of the collection period. None of the drugs administered modified the efflux of $\mathrm{Ch}$ from the hippocampus.

Basal outflow of GABA from the septum of freely moving rats was $31.0 \pm 5.28 \mathrm{pmol} / 20 \mathrm{~min}(n$ rats $=13)$ and remained stable throughout the experiment.

\section{Administration of NMDA receptor antagonists}

The intraventricular administration of the competitive NMDA antagonist CPP to rats implanted with an intracerebroventricular cannula in the right lateral ventricle and a microdialysis membrane in the hippocampus was followed by an increase in $\mathrm{ACh}$ outflow from the hippocampus. Figure $2 A$ shows the time 
course of the increase for each dose tested (1-50 nmol), expressed as percentage change from the mean of the three collection periods before CPP administration (basal outflow). The time course of $\mathrm{ACh}$ outflow in control animals injected intracerebroventricularly with $5 \mu \mathrm{l}$ saline is also shown. The effect of CPP began between 40 and $80 \mathrm{~min}$ after administration, was dose dependent in the range of 1-50 nmol (as shown in Fig. 2B) and appeared to be large and long lasting.

CPP administration elicited a complex behavior characterized by circling, and head and body weaving, superimposed on neck and limbs hypotonia and ataxia. Although a quantitative analysis of the behavioral effects elicited by the drug was not performed, their intensity appeared to be dose dependent and their time course was similar to that of the increase in $\mathrm{ACh}$ outflow. At the dose of $50 \mathrm{nmol}$ the symptomatology was so intense that we considered unethical to repeat these experiments.

No change in ACh outflow from the striatum was observed after intracerebroventricular administration of $5 \mathrm{nmol}$ of CPP (Fig. 2(').

Local application of CPP to the hippocampus via the dialysis probe $(100 \mu \mathrm{M}$ CPP, dissolved in Ringer's solution, starting after three basal samples and lasting $100 \mathrm{~min}$ ) had no effect on hippocampal ACh outflow (variations ranging between -9 and $+10 \% ; n=8$ ).

The outflow of $\mathrm{ACh}$ from the hippocampus was completely abolished by local application of the $\mathrm{Na}^{+}$channel blocker TTX $(0.5 \mu \mathrm{M}$, dissolved in Ringer's solution) via the dialysis tubing (Fig. 3). Following local administration of TTX $(0.5 \mu \mathrm{M})$ via the dialysis tubing, CPP administration ( $5 \mathrm{nmol}$, i.c.v.) did not enhance the outflow of $\mathrm{ACh}$ that gradually fell to undetectable values (Fig. 3). The effect of TTX shows that the increase in hippocampal ACh outflow brought about by CPP was dependent on propagated neuronal activity. The rats treated with both TTX and CPP displayed the same behavioral symptomatology as those treated with CPP alone, a finding indicating that either the behavioral effects did not depend on the increased ACh outflow, or that TTX did not diffuse so far as to block the effects of CPP on other parts of the hippocampus or on other nuclei.

Figure 4 shows the effect of two other NMDA and one nonNMDA antagonists on the outflow of $\mathrm{ACh}$ from the hippocampus. Figure $4 A$ shows that the competitive NMDA antagonist (D-AP7, $100 \mathrm{nmol}$, i.c.v.) increased ACh outtlow from the hippocampus $40 \mathrm{~min}$ after administration. The increase $(80 \%)$ peaked $60 \mathrm{~min}$ after administration, lasted for about $1 \mathrm{hr}$ and then gradually returned to basal values. Figure $4 B$ shows the effect of two doses of the noncompetitive NMDA antagonist MK801 (5 and $20 \mathrm{nmol}$, i.c.v.) on ACh outflow from the hippocampus. While the dose of $5 \mathrm{nmol}$ was ineffective, $20 \mathrm{nmol}$ MK801 caused an increase in ACh outflow with a maximum (about 100\%) $60 \mathrm{~min}$ after administration. The effect lasted for about $1 \mathrm{hr}$ and then returned to basal values. Figure $4 C$ shows the effect of three doses $(0.25,5$, and 20 nmol, i.c.v.) of the nonNMDA receptor antagonist DNQX on the outflow of $\mathrm{ACh}$ from the hippocampus. None of the doses tested significantly enhanced the outflow of $\mathrm{ACh}$.

\section{Intracerebroventricular administration of muscimol and $C P P$}

In order to demonstrate whether the effects of intracerebroventricular administration of CPP on ACh outflow from the hippocampus were due to an indirect action mediated via GABAergic neurons, the effect of a GABA agonist on hippocampal ACh outflow was studied.

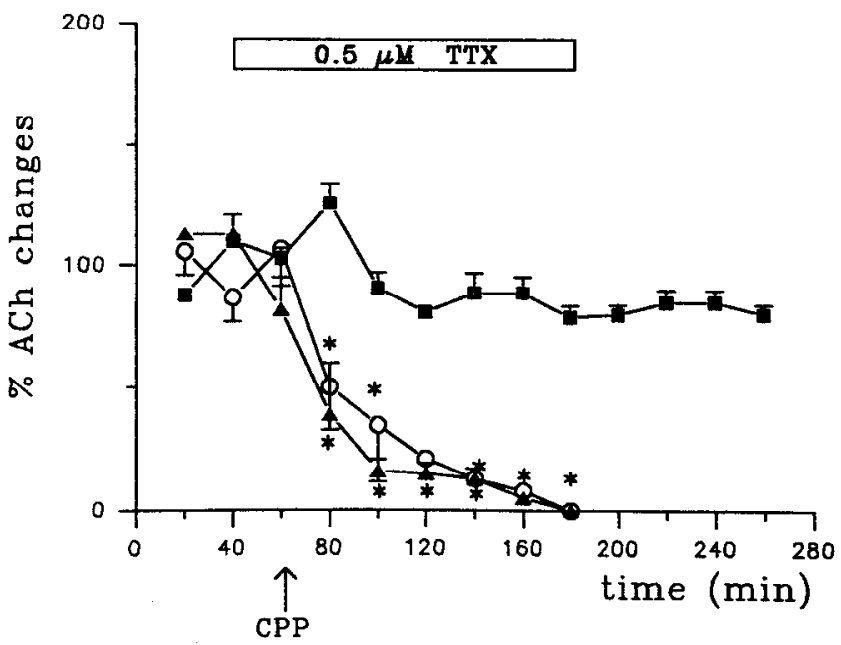

Figure 3. Local administration of TTX to the hippocampus completely blocks the effect of CPP administration. TTX perfusion $(0.5 \mu \mathrm{M}$, dissolved in Ringer's solution containing $7 \mu \mathrm{M}$ physostigmine sulfate) started $20 \mathrm{~min}$ before intracerebroventricular injection of $5 \mathrm{nmol} \mathrm{CPP}$, shown by the arrow, and lasted for a further $140 \mathrm{~min}$. ACh outflow is expressed as percentage changes over the mean of the first three basal samples, as controls (mean \pm SEM of at least four independent experiments). The time course of $\mathrm{ACh}$ outflow from control rats is reported for comparison. Data points represent controls ( $5 \mu$ l saline, i.c.v.) (solid squares), TTX $(0.5 \mu \mathrm{M}$, dissolved in Ringer's solution) (solid triangles), and TTX $(0.5$ $\mu \mathrm{M}$, dissolved in Ringer's solution) । CPP ( $5 \mathrm{nmol}$, dissolved in $5 \mu \mathrm{l}$ saline, i.c.v.) (open circles). Differences were evaluated versus the basal samples by means of ANOVA for repeated measures followed by Newman-Keuls post hoc comparison test $\left(^{*}, p\right.$ at least $<0.05$ vs basal outflow).

Figure $5 A$ shows the effect of intracerebroventricular administration of two doses of muscimol ( 1 and $5 \mathrm{nmol}$ ) on the outflow of $\mathrm{ACh}$ from the hippocampus that appeared to be biphasic: an immediate and short-lasting increase $(80 \%$ at the dose of 5 $\mathrm{nmol}$ ), followed by a long-lasting decrease ( $50 \%$ below the basal outflow at the dose of $5 \mathrm{nmol}$ ). The administration of muscimol directly to the hippocampus via the microdialysis tubing ( 100 $\mu \mathrm{M}$ dissolved in Ringer's solution) after collecting four basal samples caused an increase (233\%) in the outflow of ACh that peaked 60 min after the beginning of the perfusion and then gradually decreased (Fig. $5 B$ ).

Muscimol (5 nmol, i.c.v.) administered 20 min after CPP (5 nmol, i.c.v.) completely prevented the effect of CPP on the outflow of ACh from hippocampus (Fig. 6). As shown in Figures $5 A$ and 6 , the time course of the effect elicited by administration of muscimol and CPP was similar to that observed with muscimol alone. All the points starting from time 120 min were significantly different from the basal samples.

\section{"Dual membrane" experiments}

In order to administer the drug locally to the septum and to evaluate GABA outflow from the septum and ACh outflow from the hippocampus of the same animal, one microdialysis tubing was placed in the hippocampus and another one in the septum (see Fig. 1). The damage caused by the probe to the septal neurons was evaluated on Richardson's solution-stained septal sections. Neuron profiles and number appeared normal and no sign of inflammation was observed around the microdialysis membrane track.

Application of CPP (100 $\mu \mathrm{M}$, dissolved in Ringer's solution without physostigmine) to the septum elicited both an increase 

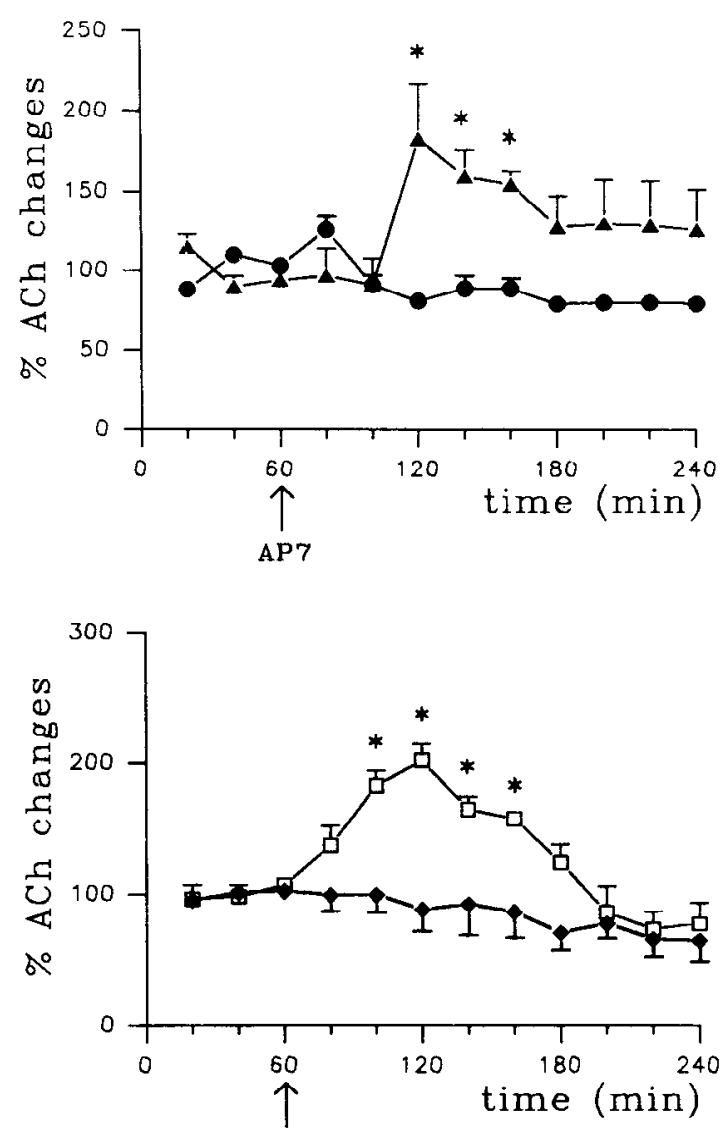

MK 801

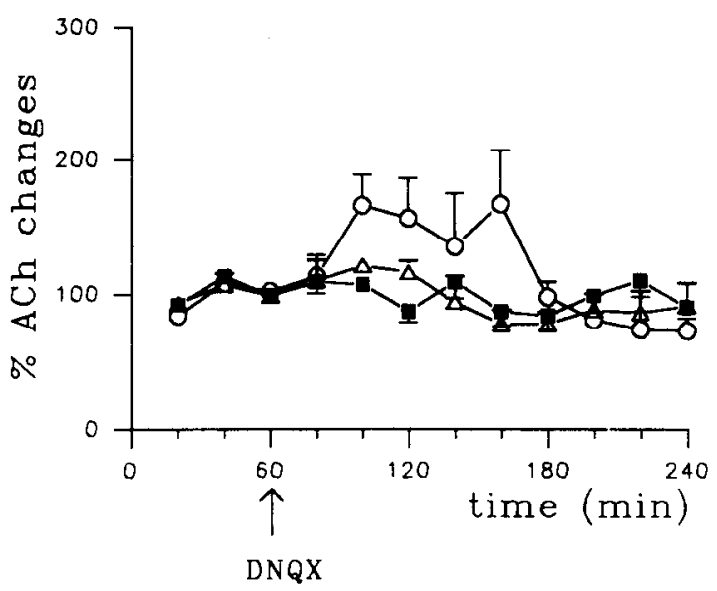

Figure 4. Effect of two NMDA and one non-NMDA antagonists on the outflow of $\mathrm{ACh}$ from the hippocampus of freely moving rats. Dialysate was collected for $60 \mathrm{~min}(3 \times 20 \mathrm{~min}$ fractions $)$ before injection of the drugs, shown by the arrow. ACh outflow is expressed as percentage changes over the mean of the first three samples, as controls (mean \pm SEM of at least four independent experiments). $A$, Effect of D-AP7. Data points represent controls $(5 \mu \mathrm{l}$ saline, i.c.v.) (solid circles) and D-AP7 ( $100 \mathrm{nmol}$, dissolved in $5 \mu \mathrm{l}$ saline) (solid triangles). ${ }^{*}, p<0.05$ versus basal samples, ANOVA for repeated measures followed by NewmanKeuls post hoc comparison test. $B$, Effect of MK801. Data points represent MK801 (dissolved in $5 \mu \mathrm{l}$ saline, i.c.v.) at $5 \mathrm{nmol}$ (solid diamonds) and $20 \mathrm{nmol}$ (open squares). ${ }^{*}, p<0.05$ versus basal samples, ANOVA for repeated measures followed by Newman-Keuls post hoc comparison test. $C$, Effect of DNQX. Data points represent DNQX (dissolved in 5 $\mu \mathrm{l}$ saline, i.c.v.) at $0.25 \mathrm{nmol}$ (solid squares), $5 \mathrm{nmol}$ (open triangles), and $20 \mathrm{nmol}$ (open circles).
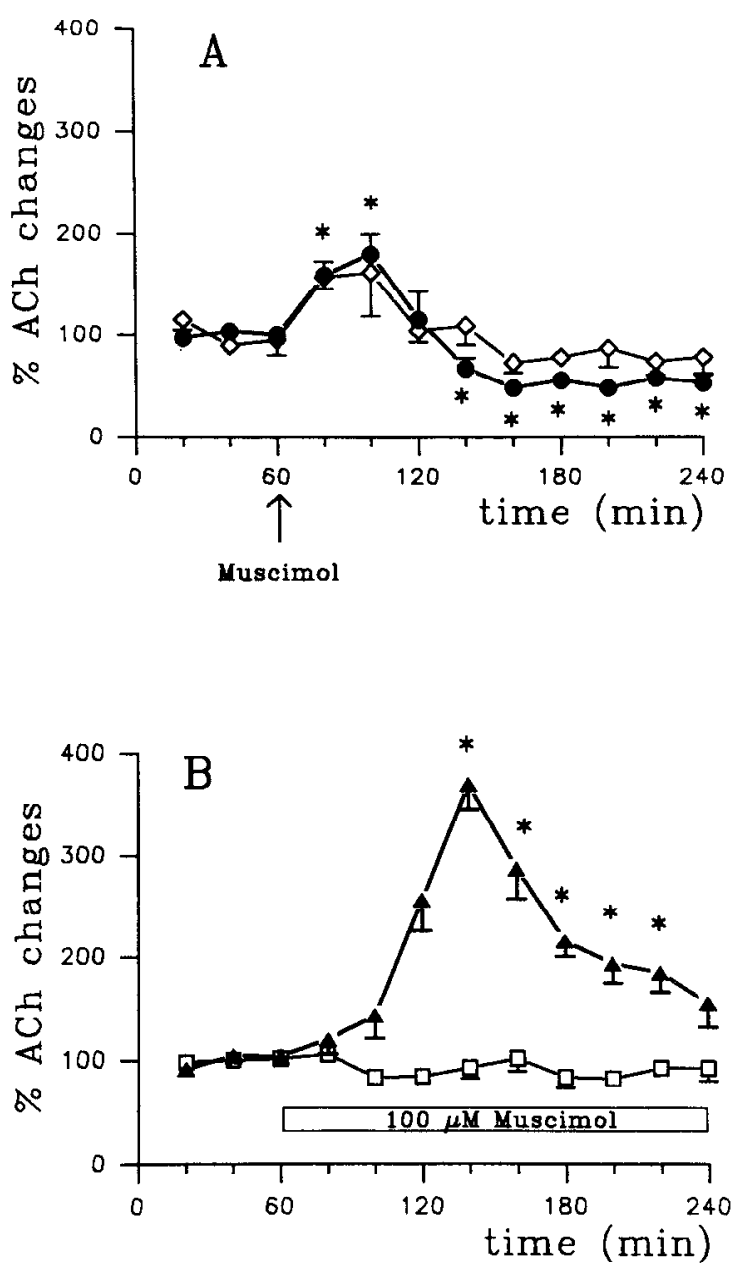

Figure 5. A, Effect of muscimol administration (dissolved in $5 \mu$ l saline, i.c.v.) on the outflow of $\mathrm{ACh}$ from the hippocampus of freely moving rats. Dialysate was collected for $60 \mathrm{~min}(3 \times 20 \mathrm{~min}$ fractions) before injection of the drugs, shown by the arrow. ACh outflow is expressed as percentage changes over the mean of the first three samples, as controls (mean \pm SEM of at least four independent experiments). Data points represent muscimol (in $5 \mu \mathrm{l}$ saline, i.c.v.) at $1 \mathrm{nmol}$ (open diamonds) and $5 \mathrm{nmol}$ (solid circles). ${ }^{*}, p$ at least $<0.05$ versus basal samples, ANOVA for repeated measures followed by Newman-Keuls post hoc comparison test. $B$, Effect of local perfusion with muscimol $(100 \mu \mathrm{M})$ on the outflow of ACh from the hippocampus of freely moving rats. Muscimol $(100 \mu \mathrm{M})$ was dissolved in Ringer's solution containing $7 \mu \mathrm{M}$ physostigmine sulfate. Muscimol perfusion started after collection of four basal samples and lasted throughout the experiment. ACh outflow is expressed as percentage changes over the mean of the first three basal samples, as controls (mean \pm SEM of six independent experiments). Data points represent controls (open squares) and muscimol $(100 \mu \mathrm{M})$ (solid triangles). ${ }^{*}, p$ at least $<0.05$ versus basal samples, ANOVA for repeated measures followed by Newman-Kculs post hoc comparison test.

in ACh outflow from the hippocampus (Fig. $7 \mathrm{~A}$ ) and a decrease in GABA outflow from the septum of the same animal (Fig. $7 B$ ). The effect of CPP on hippocampal ACh and septal GABA outflow was antagonized by the simultaneous administration to the septum of NMDA $(200 \mu \mathrm{M}$, perfused through the dialysis membrane) as shown in Figure $7, A$ and $B$. When muscimol and CPP were administered together ( $100 \mu \mathrm{M}$, dissolved in Ringer solution without physostigmine), the effect of CPP and muscimol on the outflow of GABA did not differ from that observed with CPP alone (Fig. $7 B$ ), but the effect of CPP on the outflow of ACh from the hippocampus was no longer evident (Fig. $7 A$ ). 


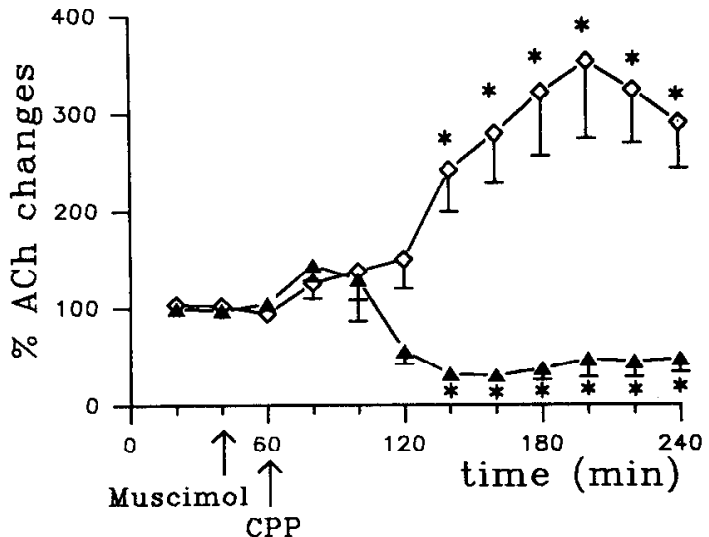

Figure 6. Effect of administration of muscimol and CPP on the outflow of ACh from the hippocampus. Solid triangles, muscimol $(5 \mathrm{nmol} / 5 \mu 1$ saline, i.c.v.) was administered $20 \mathrm{~min}$ before the administration of CPP ( $5 \mathrm{nmol} / 5 \mu \mathrm{l}$ saline, i.c.v.). Open diamonds, a curve showing the time course of the effect of CPP alone ( $5 \mathrm{nmol} / 5 \mu$ l saline, i.c.v.) on hippocampal ACh outflow is also shown for comparison. ACh outflow is expressed as percentage changes over the mean of the first three samples, as controls (mean \pm SEM of at least four independent experiments. *, $p$ at least $<0.05$ versus basal samples, ANOVA for repeated measures followed by Newman-Keuls post hoc comparison test.

When the microdialysis tubing was not positioned exactly in the septum, but in a nearby structure, neither GABA outflow from the septum nor $\mathrm{ACh}$ outflow from the hippocampus was modified by CPP (data not shown), indicating that this effect was not due to the interaction of the drug with NMDA receptors localized in adjacent structures, but rather to a direct action on receptors located in the septum.

\section{Discussion}

The aim of this research was to examine whether the septohippocampal cholinergic pathway is regulated "in vivo" by a glutamatergic input.

Our main findings were that (1) intracerebroventricular administration of the NMDA antagonists CPP, D-AP7, or MK801 increased ACh outflow from the hippocampus; (2) local administration of CPP to the hippocampus had no effect on hippocampal ACh outflow; (3) local administration to the septum of the NMDA antagonist CPP was followed by a decrease in the outflow of GABA from the septum and by an increase in $\mathrm{ACh}$ outflow from the hippocampus; and (4) administration of muscimol completely prevented the effect of CPP on hippocampal ACh outflow, but had no effect on septal GABA outflow.

Taken together, these findings suggest that the increase in hippocampal ACh outflow elicited by NMDA receptor antagonists was mediated by NMDA receptors located on GABAergic neurons of the septum. It is important to emphasize that when the dialysis tubing was positioned in an area just outside the septum, no effect on GABA or ACh outflow was detected. This finding confirms that CPP locally administered to the septum elicits its effect on GABA and ACh outflow by interacting with NMDA receptors present in the septum and not by diffusing to more distant structures. However, the relatively large diameter of the dialysis tubing that was in contact with the lateral and medial septal areas did not allow identification of the exact region of the septum where such interaction occurred. No effect was obtained perfusing CPP directly in the hippocampus. This excludes local presynaptic effect on cholinergic nerve terminals
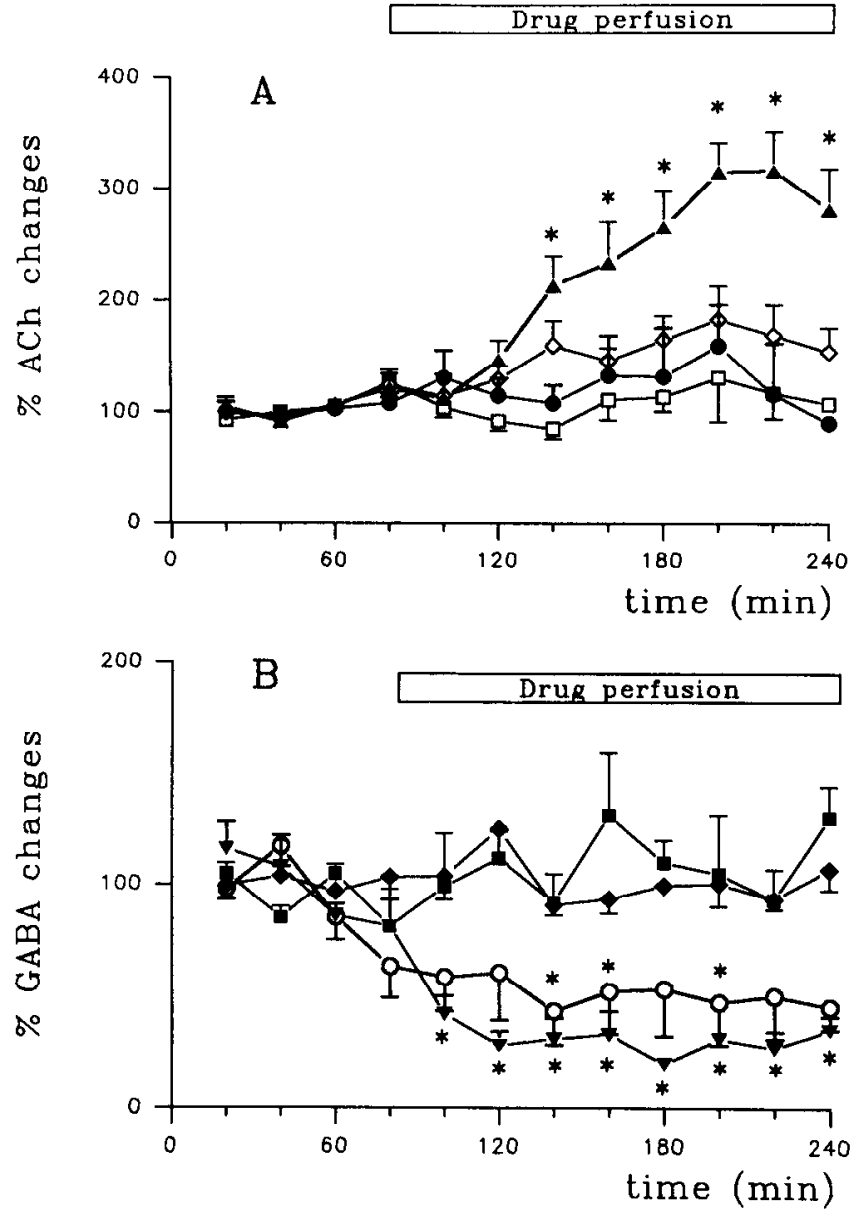

Figure 7. "Dual membrane" experiments: effect of CPP alone and CPP plus muscimol perfused through the septum via the dialysis membrane on hippocampal ACh outflow $(A)$ and septal GABA outflow $(B)$. Muscimol $(100 \mu \mathrm{M})$ and/or CPP $(100 \mu \mathrm{M})$ were dissolved in Ringer's solution without physostigmine and administered through the membrane after collection of four samples as shown by the horizontal bar. This system allowed the administration of drugs locally to the septum and the contemporaneous evaluation of their effects on GABA outflow from the septum and of ACh outflow from the hippocampus. ACh and GABA outflows are expressed as percentage changes over the mean of the first four samples, as controls (mean \pm SEM of at least five independent experiments). $A$, Each point is the mean \pm SEM of at least five independent experiments. Data points represent controls (open squares), CPP alone $(100 \mu \mathrm{M})$ (solid triangles), CPP $(100 \mu \mathrm{M})$ plus muscimol $(100$ $\mu \mathrm{M})$ (solid circles), and CPP $(100 \mu \mathrm{M})$ plus NMDA $(200 \mu \mathrm{M})$ (open diamonds). ${ }^{*}, p$ at least $<0.05$ versus basal samples, ANOVA for repeated measures followed by Newman-Keuls post hoc comparison test. $B$, Each point is the mean \pm SEM of at least four independent experiments. Data points represent controls (solid squares), CPP alone $(100 \mu \mathrm{M})$ (solid triangles), CPP $(100 \mu \mathrm{M})$ plus muscimol $(100 \mu \mathrm{M})$ (open circles), and $\mathrm{CPP}(100 \mu \mathrm{M})$ plus NMDA $(200 \mu \mathrm{M})\left(\right.$ solid diamonds). ${ }^{*}, p$ at least $<0.05$ versus basal samples, ANOVA for repeated measures followed by Newman-Keuls post hoc comparison test.

and confirms previous results that NMDA has no effect on ACh outflow from hippocampal slices (Lehmann and Scatton, 1982; Ulus et al., 1992). CPP or muscimol was administered by intracerebroventricular injection or locally to the septum. The estimated volume of ventricular space in the brain of adult rat is $200 \mu \mathrm{l}$. Therefore, after intracerebroventricular injection of 5 nmol of CPP or muscimol, the concentration of the drug in the cerebrospinal fluid was presumed to be $10 \mu \mathrm{M}$, that is, 10-fold lower than that administered to the septum via the dialysis 
membrane $(100 \mu \mathrm{M})$. However, we cannot evaluate how much of the drug was dialyzed through the dialysis membrane and diffused to the surrounding tissue, because the permeability of the membrane depends on several factors, such as the characteristics of the membrane itself, its effective surface area, and the flow rate (Benveniste, 1989). It can therefore be assumed that the doses of the drugs administered via intracerebroventricular injections were of the same order of magnitude than those administered via the membrane, as also suggested by the similar magnitude of the responses regardless of the routes of administration.

In our experiments, intracerebroventricular administration of muscimol inhibited the outflow of $\mathrm{ACh}$ from the hippocampus, confirming previous results (Wood et al., 1979) that intraseptal injection of muscimol decreases $\mathrm{ACh}$ turnover rate in the hippocampus. Furthermore, in our experiments muscimol completely prevented the increase in $\mathrm{ACh}$ outflow from the hippocampus elicited by CPP, without affecting the decrease in GABA outflow from the septum following CPP administration. Our data therefore are a further demonstration of the existence of a tonic inhibitory input on the medial septal neurons, as suggested by Vinogradova et al. (1980) and Dutar et al. (1987).

From our results and those already present in the literature, it appcars that the cholinergic septohippocampal pathway is part of a hippocampal-septal-hippocampal polysynaptic circuitry formed by an excitatory glutamatergic input (presumably from the hippocampus via the fimbria to the lateral septum; Gaykema et al., 1991), intrinsic GABAergic inhibitory neurons from the lateral to the medial septum, and cholinergic neurons projecting to the hippocampus also via the fimbria. A similar circuitry has been proposed by McLennan and Miller (1974a), who showed that the inhibition of medial septal neurons elicited by fimbria stimulation is mediated by fibers impinging on septal inhibitory interneurons. Schneggenburger et al. (1992) have demonstrated the existence not only of GABA receptors but also of nonNMDA and NMDA receptors on the soma of large medial septal cells which they identified as cholinergic. Schneggenburger et al. (1992) have also shown that all medial septal neurons display a sequence of excitatory-inhibitory postsynaptic potentials, identified as due to the activation of non-NMDA and GABA receptors, respectively. We were unable to detect changes in hippocampal ACh outflow after intracerebroventricular administration of the non-NMDA antagonist DNQX, contrary to what one might have expected from the presence of non-NMDA receptors on cholinergic medial septal neurons. Either the doses of DNQX used lacked of specificity toward non-NMDA receptors or in the awake animal summation of EPSPS and IPSPS (due to recurrent collaterals from the cholinergic neurons) produced no net change in hippocampal ACh outflow.

The central cholinergic system plays a fundamental role in memory formation (Bartus et al., 1982), and in particular the septal cholinergic neurons projecting to the hippocampus are involved in the generation of the working memory (Olton et al., 1979; Gray and McNaughton, 1983; Walker and Olton, 1984). In addition, the NMDA receptor system of the hippocampus has been implicated in the induction of long-term potentiation (LTP) (for review, see Collingridge and Bliss, 1987), and NMDA antagonists that block hippocampal LTP disrupt some forms of learning and memory (Morris et al., 1986; Morris, 1989; Davis et al., 1992). It has also been reported that $\mathrm{ACh}$ potentiates NMDA-mediated synaptic activity in the hippocampus (Markram and Segal, 1990). This finding suggests some interde- pendence between the effects of hippocampal ACh on memory processes and the NMDA-dependent mechanisms of synaptic plasticity responsible for LTP and memory formation. Although NMDA antagonists increased the outflow of ACh from the hippocampus, this phenomenon might have been insufficient to reverse the well-known impairment of memory formation directly caused by NMDA receptor antagonism (Morris et al., 1986; Morris, 1989; Davis et al., 1992).

In conclusion, our results demonstrate that NMDA receptors located in the septum, probably on GABAergic intrinsic neurons, regulate the outflow of GABA, which in turn inhibits the outflow of $\mathrm{ACh}$ from hippocampal cholinergic nerve endings, and are a further demonstration of a glutamatergic-GABAergiccholinergic nature of the hippocampal-septal-hippocampal circuitry.

\section{References}

Bartus RT, Dean RL, Beer B, Lippa AS (1982) The cholinergic hypothesis of geriatric memory dysfunction. Science 217:408-417.

Benveniste H (1989) Brain microdialysis. J Neurochem 52:1667-1679. Collingridge GL, Bliss TVP (1987) NMDA receptors-their role in longterm potentiation. Trends Neurosci 10:288-293.

Cuello AC, Sofroniew MV (1984) The anatomy of the CNS cholinergic neurons. Trends Neurosci 7:74-78.

Damsma G, Lammerts Van Bueren D, Westerink BHC, Horn AS (1987a) Determination of acetylcholine in the femtomole range by means of HPLC, a post-column enzyme reactor, and electrochemical detection. Chromatographia 24:827-831.

Damsma G, Westerink BHC, Imperato A, Rollema H, De Vries JB, Horn AS (1987b) Automated brain dialysis of acetylcholine in freely moving rats: detection of basal acetylcholine. Life Sci 41:873-876.

Davis S, Butcher SP, Morris RGM (1992) The NMDA receptor antagonist D-2-amino-5-phosphonopentanoate (D-AP5) impairs spatial learning and LTP "in vivo" at in tracerebral concentration comparable to those that block LTP "in vitro." J Neurosci 12:21-34.

Dutar P, Lamour Y, Jobert A (1985) Septohippocampal neurons in the rat: an in vivo intracellular study. Brain Res 340:135-142.

Dutar P, Rascol O, Jobert A, Lamour Y (1987) Modulation of the excitability of septohippocampal terminals in the rat: relation to neuronal discharge rate. Brain Res 418:98-110.

Dutar P, Rascol O, Lamour Y (1989) Rhythmical bursting activity and GABAergic mechanisms in the medial septum of normal and pertussis toxin-pretreated rats. Exp Brain Res 77:374-380.

Gaykema RPA, Van der Kuil J, Hersh LB, Luiten PGM (1991) Patterns of direct projections from the hippocampus to the medial septum-diagonal band complex: anterograde tracing with Phaseolus vulgaris leucoagglutinin combined with immunohistochemistry of choline acetyltransferase. Neuroscience 43:349-360.

Giovannini MG, Casamenti F, Nistri A, Paoli F, Pepeu G (1991a) Effect of thyrotropin releasing hormone (TRH) on acetylcholine release from different brain areas investigated by microdialysis. $\mathrm{Br} \mathbf{J}$ Pharmacol 102:363-368.

Giovannini MG, Mutolo D, Pepeu G (1991b) Aminoacidergic modulation of hippocampal acetylcholine release. In: Monitoring molecules in neuroscience (Rollema H, Westerink B, Drijfhout WJ, eds), pp 288-290. Meppel, The Netherlands: Krips.

Giovannini MG, Bianchi L, Pepeu G (1992) NMDA receptors modulate the septo-hippocampal cholinergic pathway through GABAergic interneurons. Paper presented at the $22 \mathrm{nd}$ annual meeting of the Society for Neuroscience, Anaheim, October 25-30.

Gray JA, McNaughton N (1983) Comparison of the behavioral effects of septal and hippocampal lesions: a review. Neurosci Biobehav Rev 7:119-188

Imperato A, Di Chiara G (1984) Trans-striatal dialysis coupled to reverse phase high performance liquid chromatography with electrochemical detection: a new method for the study of the "in vivo" release of endogenous dopamine and metabolites. J Neurosci 4:966-977.

Jöels M, Urban IJA (1984) Electrophysiological and pharmacological evidence in favor of aminoacid neurotransmission in fimbria-fornix fibers innervating the lateral septal complex of rats. Exp Brain Res 54:455-462.

Krnjevic K, Ropert N (1982) Electrophysiological and pharmacolog- 
ical characteristics of facilitation of hippocampal population spikes by stimulation of the medial septum. Neuroscience 7:2165-2183.

Lamour Y, Dutar P, Jobert A (1984) Septo-hippocampal and other medial septum-diagonal band neurons: electrophysiological and pharmacological properties. Brain Res 309:227-239.

Lehmann J, Scatton B (1982) Characterization of the excitatory amino acid receptor-mediated release of ( $\left.{ }^{3} \mathrm{II}\right)$ acetylcholine from rat striatal slices. Brain Res 252:477-489.

Lenda K, Svenneby G (1980) Rapid high performance liquid chromatographic determination of amino acids in synaptosomal extracts. J Chromatogr 198:516-519.

Lewis PR, Shute CCD (1967) The cholinergic limbic system: projections to hippocampal formation, medial cortex, nuclei of the ascendic cholinergic reticular system and the subfornical organ and supra-optic crest. Brain 90:521-540.

Lewis PR, Shute CCD, Silver A (1967) Confirmation from choline acetylase analysis of a massive cholinergic innervation to the rat hippocampus. J Physiol (Lond) 191:215-224.

Malthe-Sörenssen D, Odden E, Walaas I (1980) Selective destruction by kainic acid of neurons innervated by putative glutamatergic affercnts in scptum and nucleus of the diagonal band. Brain Res 182:461465 .

Markram H, Segal M (1990) Acetylcholine potentiates responses to $N$-methyl-D-aspartate in the rat hippocampus. Neurosci Lett 113:6265.

McLennan H, Miller JJ (1974a) The hippocampal control of neuronal discharges in the septum of the rat. J Physiol (Lond) 237:607-624.

McLennan H, Miller JJ (1974b) Gamma-Aminobutyric acid and inhibition in the septal nuclei of the rat. J Physiol (Lond) 237:625-633.

Morris RGM (1989) Synaptic plasticity and learning: selective impairment of learning in rats and blockade of long-term potentiation "in vivo" by the $N$-methyl-D-aspartate receptor antagonist AP5. J Neurosci 9:3040-3057.

Morris RGM, Anderson E, Lynch GS, Baudry M (1986) Selective impairment of learning and blockade of long-term potentiation by an $N$-methyl-D-aspartate receptor antagonist, AP5. Nature 319:774-776.

Nicoll RA (1985) The septo-hippocampal projection: a model cholinergic pathway. Trends Neurosci 8:533-536.
Olton DS, Becker JT, Handlemann GE (1979) Hippocampus, space and memory. Behav Brain Sci 2:313-365.

Paxinos G, Watson C (1982) The rat brain in stereotaxic coordinates. New York: Academic.

Pepeu G (1973) The release of ACh from the brain: an approach to the study of the central cholinergic mechanisms. In: Progress in neurobiology, Vol 2 (Kerkut GA, Phillis JW, eds), pp 259-288. Oxford: Pergamon.

Schneggenburger R, Lopez-Barneo J, Konnerth A (1992) Excitatory and inhibitory synaptic currents and receptors in rat medial septal neurones. J Physiol (Lond) 445:261-267.

Segal M (1986) Properties of the rat medial septal neurones recorded "in vitro." J Physiol (Lond) 379:309-330.

Stevens DR, Cotman CW (1986) Excitatory amino acid antagonists depress transmission in hippocampal projections to the lateral septum. Brain Res 382:437-440.

Szerb JC (1967) Cortical acetylcholine and electroencephalic arousal. J Physiol (Lond) 192:329-343.

Ulus IH, Buyukuysal RL, Wurtman RJ (1992) $N$-methyl-D-aspartate increases acetylcholine release from rat striatum and cortex: its effect is augmented by cholinc. J Pharmacol Exp Ther 261:1122-1128.

Vinogradova ES, Brazhnik ES, Karanov AM, Zhadina SD (1980) Neuronal activity of the septum following various types of deafferentation. Brain Res 187:353-368.

Walker JA, Olton DS (1984) Fimbria-fornix lesions impair spatial working memory but not cognitive mapping. Behav Neurosci 98:226242.

Wood PL, Cheney DL, Costa E (1979) An investigation of whether septal gamma-aminobutyrate-containing interneurons are involved in the reduction in the turnover rate of acetylcholine elicited by substance $P$ and $\beta$-endorphin in the hippocampus. Neuroscience 4:14791484.

Wu CF, Bertorelli R, Sacconi M, Pepeu G, Consolo S (1988) Decrease of brain acetylcholine in aging freely-moving rats detected by microdialysis. Neurobiol Aging 9:357-361.

Zaczek R, Hedreen JC, Coyle JT (1979) Evidence for a hippocampalseptal glutamatergic pathway in the rat. Exp Neurol 65:145-156. 